International JOURNAL OF MULTidisciplinary RESEARCH AND ANALysis

ISSN(print): 2643-9840, ISSN(online): 2643-9875

Volume 04 Issue 12 December 2021

DOI: 10.47191/ijmra/v4-i12-24, Impact Factor: 6.072

Page No.- $1935-1943$

\title{
E-Document Archiving System with SMS Support
}

\author{
Bella Gertrude B. Alpasan ${ }^{1}$, Mary Jane V. Esimos ${ }^{2}$, Sharra Mae B. Fernandez ${ }^{3}$, Audrey Karyl P. \\ Maligang ${ }^{4}$, Sheila Mae S. Pagayonan ${ }^{5}$ April Rose A. Zaragosa ${ }^{6}$ \\ 1,2,3,4,5,6 Northern Iloilo Polytechnic State College, Estancia, Iloilo Philippines
}

ABSTRACT: The School of Institute of Information and Computer Studies is facing a problem in the submission of the documents every end of the academic year which are requirements of the Director of the IICS before signing the clearance of its faculty members. In order to fast-track the submission of the documents, an alternative solution to solve the current problem was developed, to be known as the "e-Document Archiving System with SMS Support". Descriptive research design was used to determine whether the objectives of the study were achieved while Developmental research design was used for the developed of the software. The architectural design used in this system was $n$-tier architecture. Since the developed system will be deployed into local area network connecting office the IICS building, the concerned faculty where can upload and archived documents electronically. The Director could simple download and print documents in real time. A Short Message Service (SMS) Support, was also be used, as additional feature which would play a vital role as a communicating tool, that enables to send notification to concerned faculty members particularly, which required documents and deadline of submission. Based on the result and findings, uploading and downloading of required documents were accessible in real time. The usability of the feature of the developed system was operational and accessible with effectiveness and efficiency, and the performance was appropriate for the need of the users.

KEYWORDS: Local, area, support, document, archive, developed

\section{INTRODUCTION}

Today the Institute of Information and Computer Studies produced and used large number of documents in several types. Producing, sharing, copying and archiving documents are important issue. Most of the institutions and universities handle this task manually or semi-automated. However, it is face with many problems in practice since there is not an affective document management system. It is difficult to achieve necessary documents quickly when it is required and to share these documents with others when it is needed,Başıbüyük and Ergüzen (2014).

One of the practical and important used of computer in school is electronic archiving system to improve the management of documents submitted to the head of the academic unit. The Institute of Information and Computer Studies (IICS) is using manual-based in submission and archiving all required documents. Every The IICS faculty submit the required documents before and after the deadline and delay of submission occurs.

Hence, it prompted researchers to design, develop and implement e-Document Archiving System with SMS Support for the Institute of Information and Computer Studies. It would enable the submission of required documents to become efficient. Producing the output must be accurate, which ensures the quality, confidentiality and timeliness of the documents. Through this program, the submission of the required documents will be faster and easier to manage.

This study was based on The Rapid Application Development (RAD) used as a model in the software development. A short message service (SMS) support was added to enable to send notification to the faculty the required documents and the deadline submission every end of the school year. To test the features of the developed system, a standard tool was based on ISO/IEC 2500 software characteristics were used by the end users. To evaluate the developed system, McCall's Software Quality Criteria evaluation tool was used by IT experts who tested and evaluated the developed system.

The study aimed to developed e-Document Archiving System with SMS Support to be used by the Director and Faculty of Institute of Information and Computer Studies (IICS). Moreover, it aimed to developed a web-based system that will store and 


\section{E-Document Archiving System with SMS Support}

archived all documents submitted by the faculty of IICS and can be downloaded and printed in real-time and determine the level of usability of the e-Document Archiving System with SMS Support to be used by the Director and faculty of IICS. Furthermore, the researchers aimed to evaluate the performance of the developed system in terms of time behavior and reliability provided to the end users and evaluates the developed system based on McCall's Quality Model.

\section{METHODOLOGY}

\section{A. Research Design}

This study employed the developmental and descriptive research design. Developmental research is the study of the process and impact of the specific instructional design and development efforts or a situation in which someone is performing instructional design, development or evaluation activities and studying the process at the same time. Descriptive research is aimed at casting light on current issues or problems through a process of data collection that enables them to describe the situation more completely than was possible without employing this method. It was developmental research because it involves designing and developing that was in the system. Descriptive research applied because it described the functionality of the study which will be evaluate based on its components and criteria in terms of Accuracy, Reliability, usability, efficiency and user friendliness.

Aside from the developmental and descriptive research, a software development model was adapted.

\section{B. Software Development Life Cycle (SDLC)}

Software Development Life Cycle (SDLC) is a series of phases that provide a common understanding of the software building process. How the software will be realized and developed from the business understanding and requirement elicitation phase to convert these business ideas and requirements into function and feature until its usage and operation to achieve the business needs. The good software engineer should have enough knowledge on how to choose the SDLS model based on the project context and the business requirements (Sami, 2012).

The researcher used the Rapid Application Development Model (RAD) allowing the usable system to be produced in a short period of time.

The RAD model started with understanding and defining the client's need, and moves through the four phases namely; Requirements Planning Phase, the User Design Phase, the Rapid Construction Phase, and last the Cutover Phase. Testing must be involved early in the program and through the development work. Throughout these phase, the researcher continuously reviews and modernizes the project plan, carefully controlling all changes along the way. Must assess the risk of the project during the completion of each cycle, and review the current understanding of the client's business needs throughout the project. RAD used a prototyping approach in the software development to help users visualize and request changes to the system as it is being developed, allowing applications to develop iteratively. Figure 1 shows the RAD model.

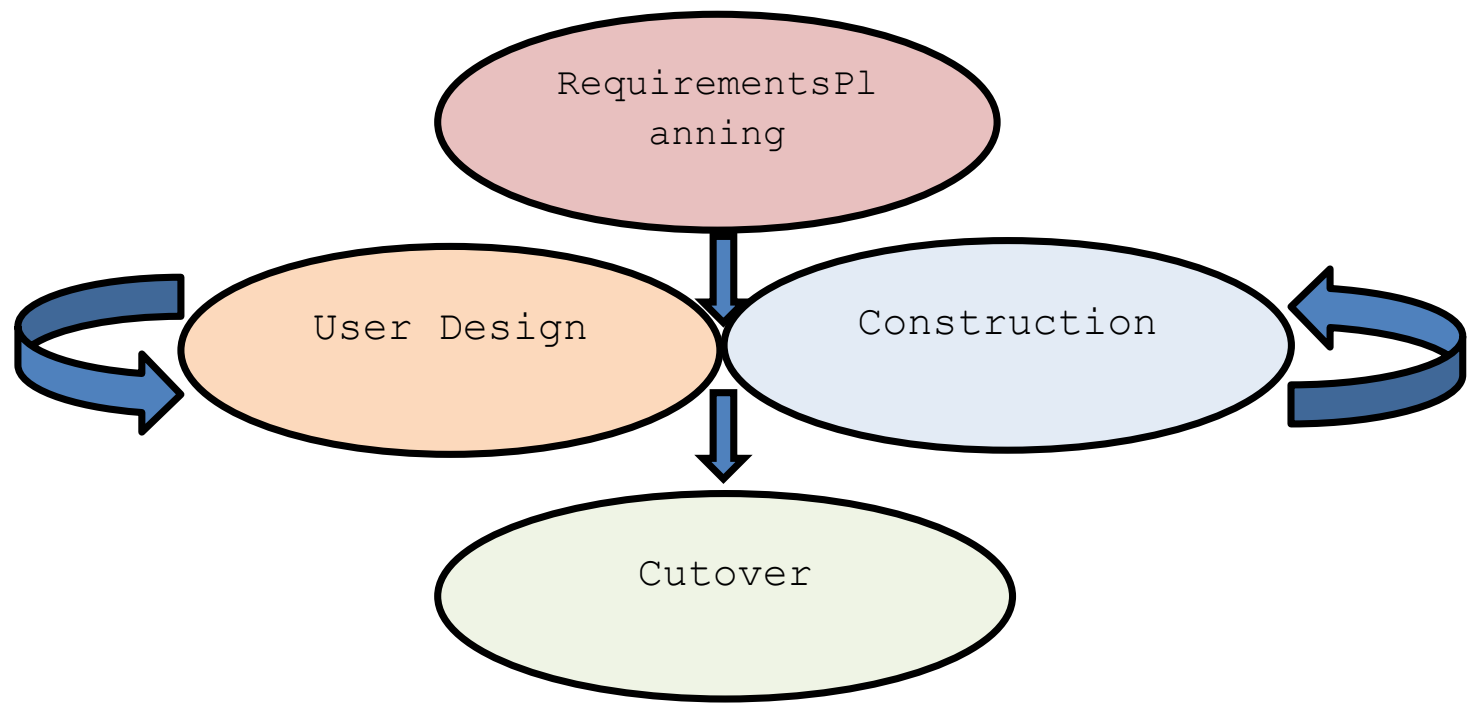

Figure 1.The Rapid Application Development Model Requirements Planning (RP) Phase

\section{Requirements Planning Phase}

Requirement Planning Phase (RP) combines elements of the system planning and systems analysis phases of the Systems Development Life Cycle (SDLC). Users, managers, and IT staff members discuss and agree on business need, project scope, constraints, and system requirements (vijaynts, 2013). 


\section{E-Document Archiving System with SMS Support}

The RP stage begins with a series of meeting with the Director of IICS. These meetings introduce the development process by establishing a mutual understanding of the objectives of the development project in common and the system in particular.

The requirements planning stage should result in a list of entities as well as the action diagrams that will define the relationship between processes and data elements.

In the requirements planning phase, users and researchers meet to identify objectives of the developed system and to identify information requirements arising from those objectives. This phase requires intense involvement from both groups.

\section{User Design (UD) Phase}

During this phase, user interacts with system and analysts and develop models and prototypes that represent all system processes, inputs, and outputs. It is continuous interactive process that allows users to understand, modify, and eventually approve a working model of the system that meets their needs (D Murguia, 2013).

The objectives of the UD stage are (a) to analyse in detail business activities associated with the developed system area; (b) to analyse in detail the business data associated with the developed system area; (c) to develop the system structure in terms of the automated and manual functions that will comprise the system; (d) to develop proposed screen layouts for the most important automated functions; (e) to select the appropriate construction approach for the system and; (f) to prepare a work plan defining the steps necessary for transition of the system, the effort required to perform these steps, and a schedule by which these steps can be completed. The UD stage produces a detailed system area model, an outline system design, and an implementation plan.

The following task was conducted under this phase.

1. Data Modeling refers to the practice of documenting software and business system design. The "modeling" of these various system and processes often involve the use of diagrams, symbols, and textual references to represent the way the data flows through a software application or the Data Architecture within an enterprise. Data modeling also includes practices such as business process modeling which deals with larger conceptual business process and decision making flows of entire organization (www.dataversity.net, 2017).

This study uses Entity Relationship Diagram (ERD) it shows the relationships of entity sets stored in the database and describing the data or information aspects of a business domain or its process requirements. In this study, there are four entities: the faculty_User, Admin_User, SMS_Notification as dependent or strong entity, and the Docs_Collections as the associative or weak entity.

Relationships are set between among these entities through cardinalities. Thus, the following relationship are defined. There is one-to-many relationship between faculty_User and Admin_User to the Docs_Collection which means that for every Faculty_ID and Admin_ID there is one-to-one relationship between SMS_Notification to Docs_Collection which means that Docs_Collection has SMS_Notification. Figure 2 below shows the Entity Relationship Diagram of the developed System.

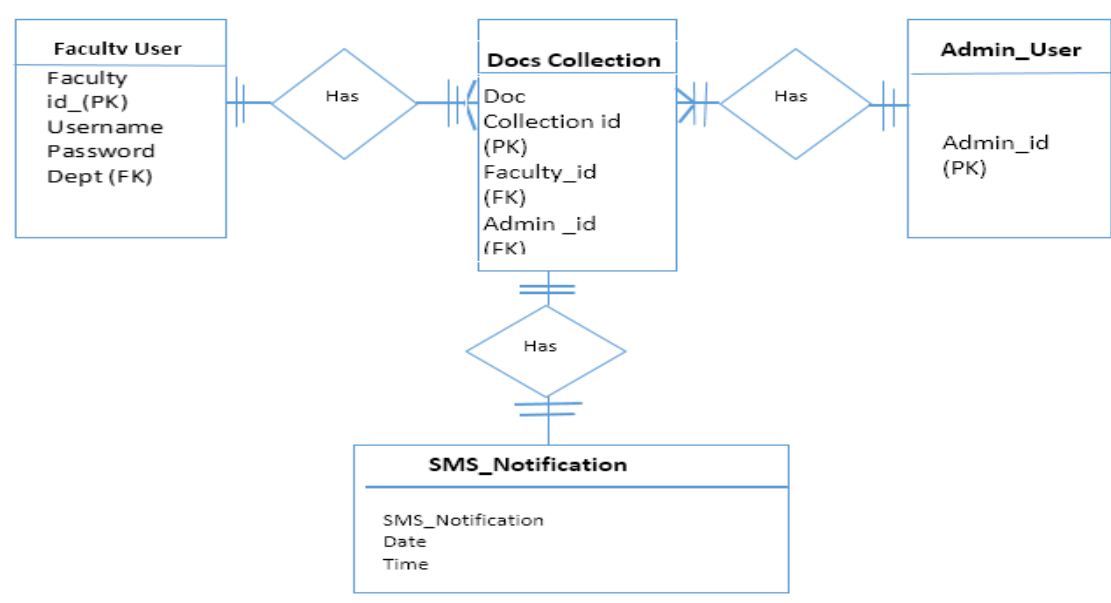

Figure 2. Entity Relationship Diagram of the Developed System.

2. Process Model. Software design is the process in which an agent creates a specification of software artificial, intended to fulfill the design, using a set of primary components and subject to constrained. It may refer either "all the actors involved in conceptualizing, framing, implementing and eventually stabilize complex system "or" the activity following requirements specification and before programming in software engineering process". 


\section{E-Document Archiving System with SMS Support}

The intent of the developed system was based on the requirements as provided by the users during the compilation of the requirements.

Software development is applicable in a data flow diagram which will be very useful to describe the relationship between the users and developed system. The proceeding model is a core illustration is structured analysis and design. Also called a Data Flow Diagram (DFD) wherein it shows the flow of information through a system. Every process converts the inputs to outputs.

In this study, the users are the following;

a)Director and the b)Faculty.

Through this developed system, the Director or the personnel in-charge, as a primary user has the full authority to control the proposed system, can approved/disapproved the registration, notify the faculty, download the submitted documents, set the documents needed in every academic year and can print a e-documents in real time.

The faculty members who are currently working on their designated room and class are the secondary users of the proposed system. The Institute of Information and Computer Studies has an existing Local Area network (LAN). The users can easily upload the e-document in real time.

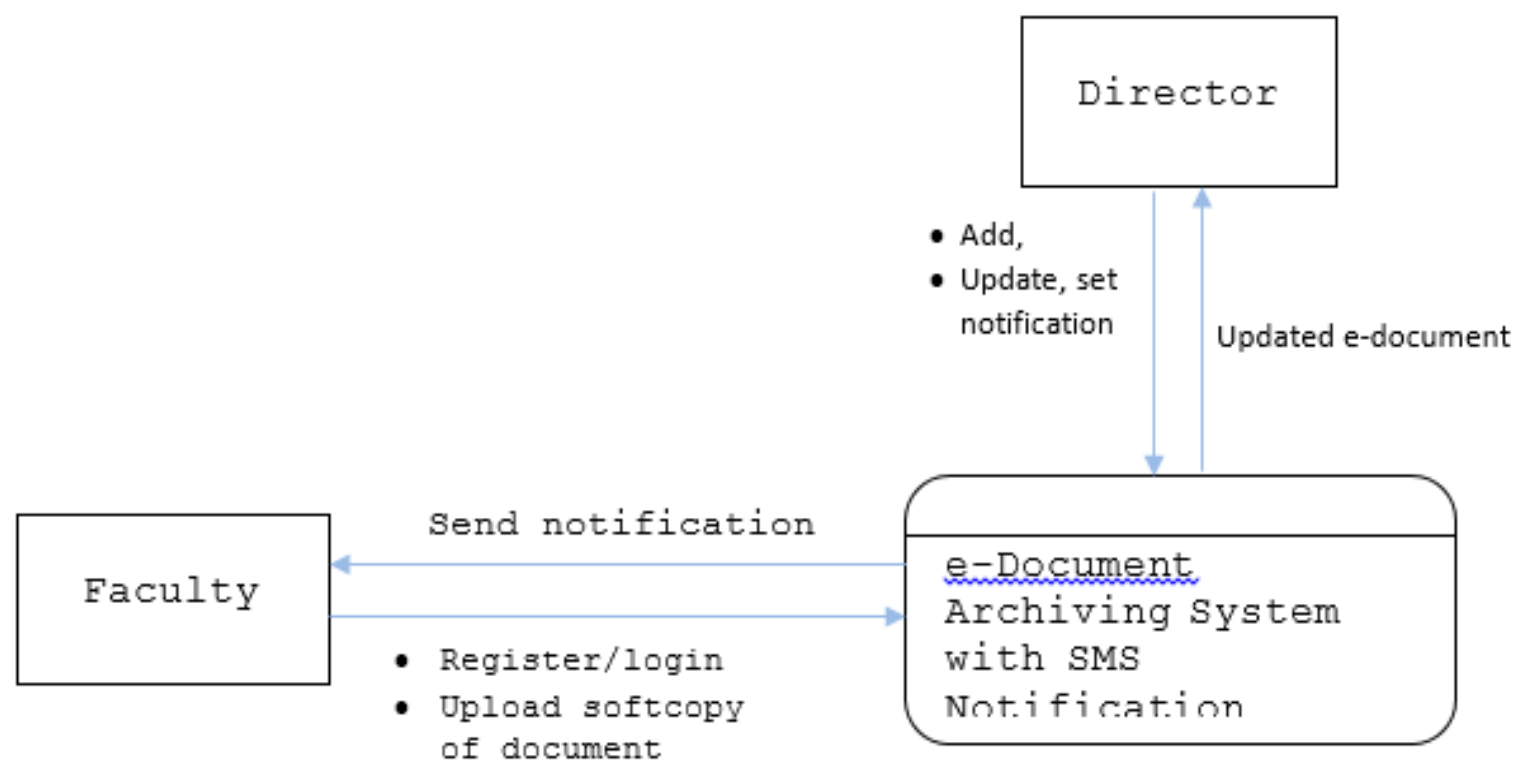

Figure 3.The Context Data Flow Diagram of the Developed System

3. Logical Architectural Design. The developed system used to run in N-tier architecture which is a Client-Server architecture combined with the layered architecture.

The design consists of three layers; the presentation layer, application layer and the logic layer also known as the business layer, and the database layer.

a. Presentation Layer. The top-most level of the application is the user interface. The main function of the interface is to translate tasks and results to the user to be understood. The developed system will design a separate presentation layer for each web application layer, its presentation layer delivers different experience depending on the device which automatically identifies the devices used whether a Smartphone, tablet, netbook, and laptop. The developed e-document Archiving System with SMS Support was made to run and locally hosted by the department. It was designed in a web-based environment which can be accessed via web browser. The faculty have direct access to the services offered by the developed system. A mobile application that connects to a server typically was connected to a web server that sent and received. It will then retrieve records from the database which was developed in PHP and MySQL as database server.

b. Application and Logic Layer. This layer coordinates the application process commands, makes logical decisions and evaluations, and performs calculations it also moves and process data between the two surrounding layers.

c. Database Layer. This is where all the collection of the documents was be stored and retrieved from a database or file system. This is where all the information and records of the faculty and the uploaded documents was be stored and retrieved from a database. The information is then passes back to the logic layer for processing, and then eventually back to the user. Figure 3 below shows the Logical Architecture Design of the Developed System. Figure 4 shows the N-tier application architecture of the developed system. 


\section{E-Document Archiving System with SMS Support}

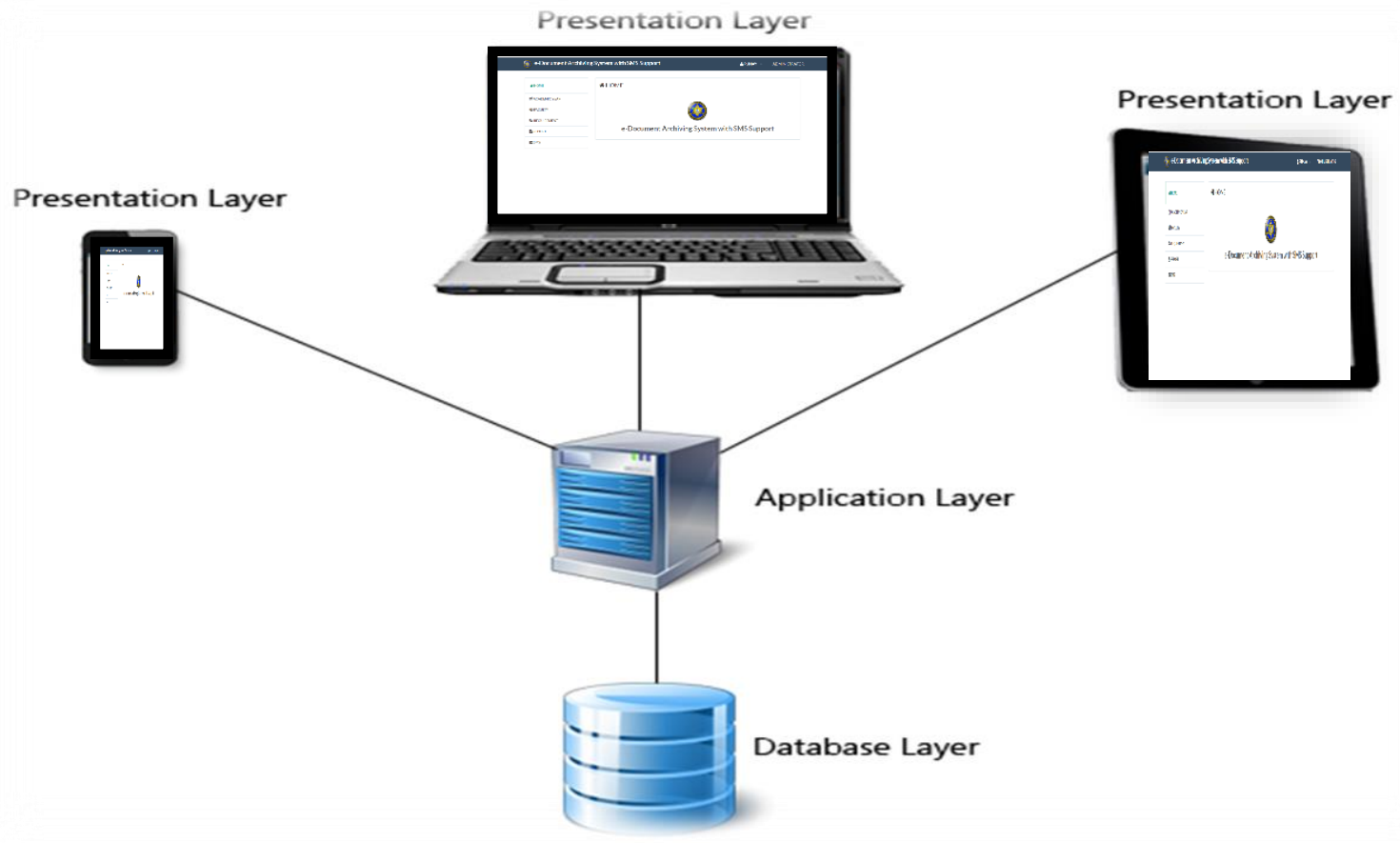

Figure 4.The Logical Architecture Design of the developed e-document Archiving System with SMS Support

4. Physical Network Topology. A physical topology refers to the interconnected structure of a local area network (LAN). The method employed to connect the physical devices on the network with the cables, and the type of cabling used, all constitute the physical topology. This contrasts with logical topology, which describes a network's media signal performance. The faculty will have a direct access to the services offered by the developed system. A wireless router will be used for connectivity for the clients who have laptops. A GSM-capable modem was attached to the server computer to facilitate notification to the outside clients, it will need GSM-capable cell phones to send SMS notifications. Figure 5 shows the physical network topology of the developed system.

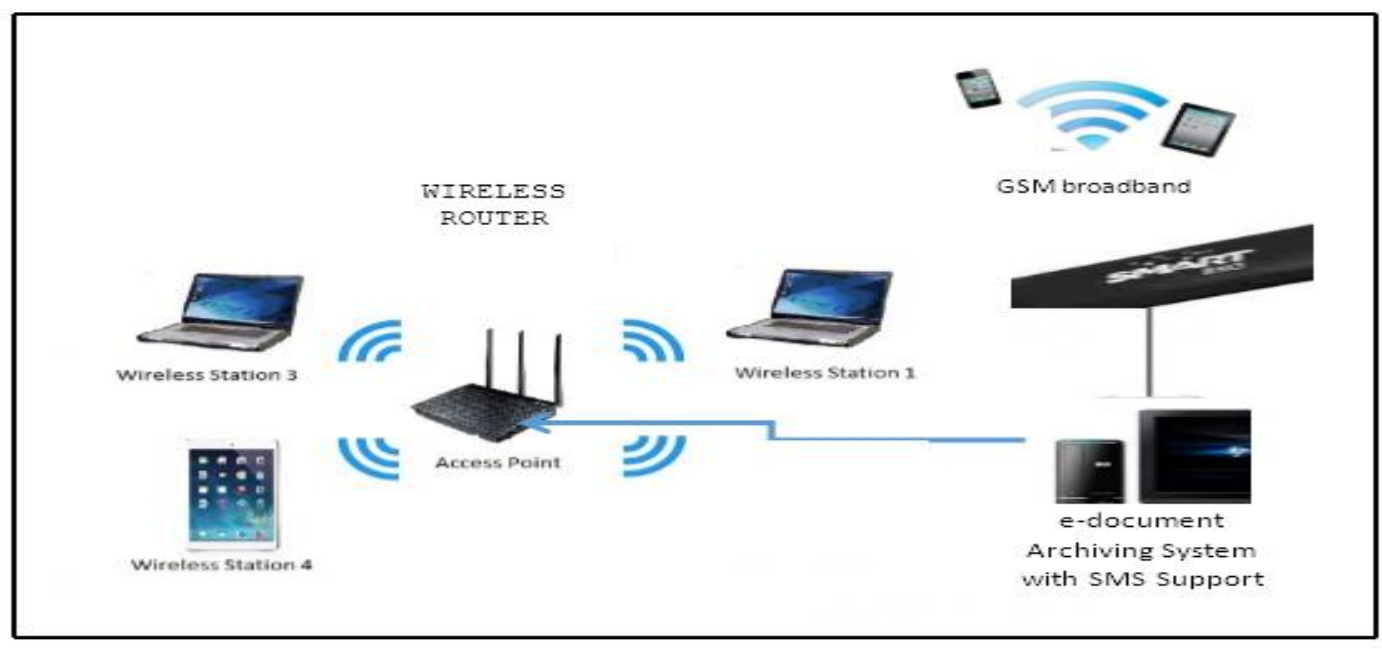

Figure 5.The Physical Network Topology of the e-document Archiving System with SMS Support.

\section{Rapid Construction (RC) Phase}

The objective of the Rapid Construction Phase are (i) minimising development cost by optimising resources and avoiding unnecessary scrap and work (ii) Achieving useful versions (Alpha, Beta and other test releases) as rapidly as practical (iii) achieving adequate quality as rapidly as practical. The activities of the RC stage involves, resource management, control and process optimization, complete component development and testing against the defined evaluation criteria and assessment of product releases against acceptance criteria for the version. The Rapid Construction Phase consist of the following stages.

(a) Preparation for Rapid Construction: this where development environment be complete include work areas for the system developer and the software to be used. 


\section{E-Document Archiving System with SMS Support}

The developed design system will used a web-based environment. The researcher had used a personal computer which served as the server. The XAMPP application package are downloaded and installed to the server computer.

The XAMPP are composed of Apache, Web - Server, Pearl, and MySQL for the database and the PHP as the server-side scripting language, a Microsoft Window operation system web development environment. These application allowed to the researcher to developed and test to their system.

A globe tattoo and other packet Wi-Fi are needed by the researcher to connect their computer, for the SMS support as additional feature, this will be attached to the server side as to notify in the client side.

(b) Construction of System prototype. The detailed of the design of each function is completed, based on the requirement of the end - users. Software to implement the automated function is developed and tested. The development Interface design will include the detailed of each function and purpose that was based on the requirement of the school and to the faculty as the end users.

(c) Testing and Evaluation, and System Documents. This task involves developing the necessary test data that would verify the operational capacity of the system. This data will be used during the integration of the developed system and acceptance tests. Documentation explaining how the system will be operated by users and computer operations personnel will be produced. Suggestions from the end users were acceptable and revision of System Prototype will be documented.

The developed system have undergone series of evaluation by the IT experts, faculties and the Director of IICS, allowing them to use the actual prototype. After the testing, testers have been provided sets of questionnaires to allow them to evaluate user's experience which include the user's acceptability, functionality and overall accessibility of the system.

This research study used Questionnaire which was based on McCall's Quality Model for characterizing the quality attributes of a software product. The questionnaires were given to three IT experts for testing and evaluation. A scale of 1 to 5 was used respectively to identify the level of performance.

To evaluate the system in terms of its reliability, functionality, efficiency and its overall acceptability. A questionnaire was administered to faculty of IICS. These questionnaire was based on the ISO/IEC 25010 standard that describes a software quality model which categorizes software quality into six characteristics (factors) and were subdivided into sub-Characteristics (criteria). A 5-point Likert scale comprising of 1 as Poor and 5 as Very Good will be used.

The researchers use the Mean to determine the level of user's experience and performance of the system.

The formula used in computing the mean is:

$$
\bar{X}=\frac{\sum X}{n}
$$

where $\bar{x}$ is the mean

$\sum \mathbf{x}$ is the summation of individual raw scores

$\mathrm{n}$ is the number of population

The obtained mean score was interpreted using the following verbal descriptions:

For User Acceptance and Expert Testing:

$\begin{array}{ll}\text { Mean Score } & \text { Verbal Description } \\ 4.21-5.00 & \text { Very Good } \\ 3.41-4.20 & \text { Good } \\ 2.61-3.40 & \text { Average } \\ 1.81-2.60 & \text { Fair } \\ 1.00-1.80 & \text { Poor }\end{array}$

\section{SOFTWARE EVALUATORS}

In this study, the researcher identified users to evaluate the system. The first group of evaluators consists of three (3) experts coming from the IICS and was a part of the evaluator's team which helped the researcher identify if it meets the users requirement and satisfaction, the user interface design, as well as to test the systems reliability, efficiency, and functionality of the developed system. This group of experts was given questionnaire based from McCall's software evaluation criteria to evaluate the system. The second group of users was composed of eleven faculty members coming from the IICS. This group of people was also given questionnaire based on ISO/IEC 25010 software characteristics to test and evaluate the system.

\section{Cutover Phase}




\section{E-Document Archiving System with SMS Support}

Resembles the final tasks in the SDLC implementation phase, including data conversion, testing, changeover to the new system, and users training. Compared with the traditional methods, the entire process is compressed. As a result, the new system is built, delivered, and placed in operational much sooner (D Murguia, 2017).

As a result, the new system was built, delivered, and placed in a faster operation.

After the beta testing of the system prototype by the selected jury, it was be subjected to conformity test with the IICS Director, the faculties was now be the end users of the developed system. Revisions and changes were made based on the feedbacks and suggestions coming from the experts and from the end users. Minimal revisions were applied to meet the exact time frame. After the acceptance, and the product of the developed system will be ready for deployment.

This includes the hardware requirements and network infrastructures. The presence of IICS Director and Faculty was present during the deployment.

The user's manual was prepared by the researcher and turned over to the user as well. Series of testing was made to enable them to be familiar with the developed system.

\section{Maintenance Phase}

The developed system lies in the availability of the IT personnel who possess programming skills for the maintenance of the system. A user's manual was made for the end users reference.

Maintenance must be kept up rigorously at all times. Users of the system should keep up-to-date concerning the latest modification and procedures.

\section{RESULTS AND DISCUSSION}

Level of Usability of the e-Document Archiving System with SMS Support among the Identified user group in terms of Learnability, Operability and Accessibility.

Table 1 shows the mean for the level of usability of the e-Document Archiving System with SMS Support among the identified user groups in terms of learnability, operability and accessibility.

Table 1.The level of usability of the developed system in terms of Learnability, Operability and Accesssibility

\begin{tabular}{|c|c|c|}
\hline Implimentation Indicators & Mean & Verbal Interpretation \\
\hline a. Learnability & 4.82 & Very Good \\
\hline b. Operability & 4.64 & Very Good \\
\hline c. Accessibility & 4.55 & Very Good \\
\hline
\end{tabular}

$\begin{aligned} & \text { Legend: } 1.00-1.80 \text { (Poor); } 1.81-2.60 \text { (Fair); } \\ & 2.61-3.40 \text { (Average); } 3.41-4.20 \text { (Good) } \\ & 4.21-5.00 \text { (Verv Good) }\end{aligned}$

The result showed that the e-Document Archiving System with SMS support had a high level of usability in terms of learnability which had a mean value of 4.82 which was verbally interpreted as "very good". The operability has the mean value of 4.64 and verbally interpreted as "very good" while the accessibility has a value of 4.55 which was verbally interpreted as "very good".

Level of Performance of the developed e-Document Archiving System with SMS Support in terms of Time Behavior and Reliability of information provided to End-Users

The following table presented the mean of the performance of the e-Document Archiving System with SMS Support in term of time behavior and reliability of the information provided to the respondents.

Table 2. Level of performance of the developed system in terms of time behaviour and realiability of information to its endusers

\begin{tabular}{|l|l|l|}
\hline Implimentation Indicators & Mean & Verbal Interpretation \\
\hline a. Time Behavior & 4.64 & Very Good \\
\hline b. Reliability & 4.73 & Very Good \\
\hline
\end{tabular}

$$
\begin{gathered}
\text { Legend: } 1.00-1.80 \text { (Poor); } 1.81-2.60 \text { (Fair); } \\
2.61-3.40 \text { (Average); } 3.41-4.20 \text { (Good); } \\
4.21-5.00 \text { (Very Good) }
\end{gathered}
$$




\section{E-Document Archiving System with SMS Support}

The result showed that the performance of the e-Document Archiving System with SMS Support in terms of time behavior had a mean value of 4.64 which was interpreted as "Very Good" while for the reliability it has a mean value of 4.49 which was interpreted as "Very Good".

\section{On the evaluation of the expert with regards to the developed system based on McCall's Software Quality Model}

Table 3 shows the evaluation of the experts to the developed system. The table reflects the mean score rated by the experts:

Table 3 .The evaluation of the expert with Regard to the developed system using McCall's Quality Model

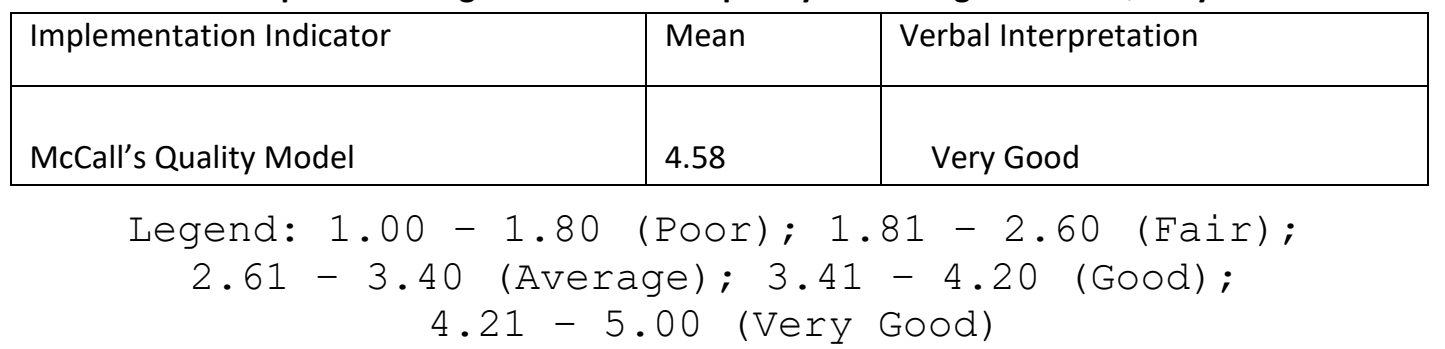

The rating of the experts with regards to the e-Document Archiving System with SMS Support has the computed mean of 4.58 and interpreted as Very Good. These findings revealed that the System is equipped with the features needed to provide information needed by the School of Institute of Information and Computer Studies.

\section{CONCLUSION}

The present investigation has the following findings:

The result of the developed system is 4.74 which is interpreted as Very Good. The finding implied that the degree in which the functions facilitate had accomplished the specified task and objectives of the developed system of the specified user in uploading and downloading the electronic archiving system of the Institute of Information and Computer Studies.

The usability of the proposed features of e-document Archiving System with SMS Support has a computed mean of 4.67 which is interpreted as Very Good. The findings implied that the degree in using the SMS Support can be used by specified users to achieve specified goals with effectiveness and efficiency.

The performance of the developed system in terms of time behavior have the computed mean of 4.64 and reliability have the computed mean of 4.73and interpreted as Very good. This simply implied that the degree in which the response and processing time in performing its functions, meet the desired and expected the requirements by the end users. It showed that the system are users friendly and fully functional.

Based on the interpretation that was discussed in the preceding chapter, the following conclusions were arrived:

The features of the e-Document Archiving System with SMS Support were very usable in terms of archiving of documents with decision-making. The features of the e-Document Archiving System with SMS Support were able to secure all school data and information and made them readily and quickly available for use by the executives which were bases for decision-making.

The graphical user interfaces and the entire design of e-Document Archiving System with SMS Support were indeed user-friendly and adaptable for the executives. When the system was used, the menus and icons were very clear, understandable and easy to use for the end users. The findings implied that the degree in which using the features of e-Document Archiving System with SMS Support can be used by specified users to achieve specified goals with effectiveness, efficiency. Features were easy to operate and controlled, wherein reports generated by the system such as documents viewing, retrieved and printed in real-time by the Secretary.

The findings implied that the degree in which the response and processing time and throughput rates of a product or system, when performing its functions, meet requirements using the developed e-Document Archiving System with SMS Support is very good.

Provide director an easy way to view the submitted documents of every faculty anytime. From the findings and conclusions of the study, the following recommendations were strongly suggested:

Since automation and computerization is adapted and used in most offices and schools, it maybe suggested that the eDocument Archiving System with SMS Support be implemented and to be used by school of Institute of Information and Computer Studies to help the Director and faculty in managing and archiving reports and other important tasks. The Institution may conduct trainings to the intended users for the familiarization of the system especially during data entry of important inputs for the system to work. 


\section{E-Document Archiving System with SMS Support}

1. The school of IICS may continue to update the system which may help to maximize its potential and improve its functionalities, security and efficiency.

2. The school may implement Parallel Testing of the system to verify its accuracy and to check for errors that may occur during the process.

3. The future researchers, it is also recommended that additional feature will be developed for the improvement of the developed system.

\section{REFERENCES}

\section{A. Books}

1) Bueno, D. (2016). Educational Research Writing Made Easy. Quezon City, Philippines: Great Books Trading, p. 102-103

2) Fox, W. \&Bayat, M.S. (2007) “A Guide to Managing Research" Juta Publications, p.45 https://research-methodology.net/descriptive-research/

3) Richey, R.C., KLEIN, J.D., NELSON, W.A., (2004), DevelomentalResearch:Studies of Instructional Design and Development, $2^{\text {nd }}$ edition, Publisher: Lawrence Erlbaum Associates, pp.1099-1130

https://www.researchgate.net/publication/263963734_Developmental_research

\section{B. Online Sources}

1) Administrator. (2017). Retrieved from http://www.collinsdictionary.com/dictionary/english/administrator

2) Documents. (2017). Retrieved from http://www.collinsdictionary.com/dictionary/english/document

3) e-Archiving. (2014). Retrieved from http://www.docman.ro/en/services/electronical-archiving

4) Faculty. (2018, May 21). Retrieved fromhttp://www.meriam-webster.com>faculty. Short Message Service (SMS). (2017, February 27). Retrieved from: http://www.loc.gov>fdd >fddd00043

5) System. (2014). Retrieved from: http://www.yourdictionary.com/system

6) Data Archiving (2015, September 24). Retrieved from: http://www.searchdatabackup.techtarget.com

7) Data Modeling (27 November, 2017), Retrieved from: http://www.dataversity.net $>$ what-is-data-modeling Mohamed Sami, (15 March, 2012) Software Development Life Cycle Models and Methodology. Retrieved from: http://melsatar.biog $>2012 / 03 / 15$

8) Vijaynts, (04 June, 2013) Requirements Planning Phase. Retrieved from: http://testingtypes.wordpress.com>tag

9) D Murguia,(22 May, 2013) User Design (UD) Phase. Retrieved from: http://testingtypes.wordpress.com>tag

10) Vijaynts, (04 June, 2013) cutover phase. Retrieved from: http://testingtypes.wordpress.com>tag

\section{Unpublish Thesis}

1) Vandika, A. Y., Kurniawan, A. \&Saputra, A. K. (2016).

2) E-Archiving: Digital Storage Media.International Conference on Engineering and Technology Development, Bandar Lampung, Indonesia. Retrieved from :researchgate.net; http://www.researchgate.net>publication

3) Yousif, N. (2010). A Web-Based Electronic Filing System using Conversion of Image File to Text File approach. Retrieved from University of Malaya Official Website; http://repository.um.edu.my/477/1/WGA070028.pdf

4) Konstantinos M, (2015). Records Management and Electronic Records Management. Retrieved from Published Master Thesis Linnaues University; http://www.diva-portal.org/smash/record.jsf

5) Ragaisis, S., Birstunas, A., Mitasiunas, A., \&Stockus, A. (2018 May) Electronic Archive Information System. Retrieved from University of Vilnius, Lithuania; http://www.ceur-ws.org >Vol-924>paper11

6) Demirtela, H ,Bayram, O.G , (2014) . Efficiency of electronic records management systems: Retrieved from Ankara University, Faculty of Letters, Information and Records Management Official Website; https://www.sciencedirect.com/science/article/pii/S1877042814040701 